\title{
Spinal cord anomalies in patients with anorectal malformations without severe sacral abnormalities or meningomyelocele: outcomes after expectant, conservative management
}

\author{
Kristiina Kyrklund, MBChB, PhD, MEd, Mikko P. Pakarinen, MD, PhD, Seppo Taskinen, MD, PhD, \\ Reetta Kivisaari, MD, PhD, and Risto J. Rintala, MD, PhD \\ Department of Pediatric Surgery, University of Helsinki, Hospital for Children and Adolescents, Helsinki, Finland
}

\begin{abstract}
OBJECTIVE The goal of this study was to determine the significance of spinal cord anomalies (SCAs) in patients with anorectal malformations (ARMs) by comparing the outcomes for bowel function, lower urinary tract symptoms (LUTS), and lower-limb neurological abnormalities to these outcomes in patients with similar ARMs and a normal spinal cord.

METHODS The spinal cord MRI records of female patients treated for vestibular and perineal fistula (VF/PF) and male patients with rectourethral fistula (RUF) at a single center between 1983 and 2006 were reviewed. Bowel function and LUTS were assessed by questionnaire. Patients with extensive sacral anomalies or meningomyelocele were excluded.
\end{abstract}

RESULTS Of 89 patients (median age 15 years, range $5-29$ years), MRI was available in $90 \%$ ( $n=80 ; 40$ male patients with RUF), and $80 \%$ of patients returned the questionnaire ( $n=64 ; 31$ male patients with RUF). Spinal cord anomalies were found in $34 \%$, comprising a filum terminale lipoma in $30 \%$, low conus medullaris in $10 \%$, and thoracolumbar syrinx in $6 \%$. Bowel functional outcomes between patients with SCAs $(n=23)$ and those with a normal spinal cord $(n=41)$ were not significantly different for soiling $(70 \%$ vs $63 \%)$, fecal accidents ( $43 \%$ vs $34 \%$ ), and constipation ( $57 \%$ vs $39 \%$; $p=$ not significant for all). The LUTS, including urge ( $65 \%$ vs $54 \%)$, urge incontinence (39\% vs $24 \%)$, stress incontinence ( $17 \%$ vs $22 \%$ ), and straining ( $32 \%$ vs $29 \%$ ) were also comparable between groups ( $p=$ not significant for all). No patients developed lower-limb neurological abnormalities.

CONCLUSIONS The results suggest that the long-term functional outcomes for patients with SCAs who had VF/PF and RUF may not differ significantly from patients with the same type of ARMs and a normal spinal cord. The results favor a conservative approach to their management in the absence of abnormal neurological findings in the lower limbs.

http://thejns.org/doi/abs/10.3171/2016.4.SPINE1641

KEY WORDS anorectal malformations; tethering; spinal cord; congenital

$\mathrm{S}$ PINAL cord anomalies (SCAs) affect approximately $26 \%-50 \%$ of patients with anorectal malformations (ARMs), $5,14,23,34$ and are found most often among patients with severe ARMs, ${ }^{14}$ but their management remains controversial. ${ }^{25}$ It has previously been suggested that the natural history of a tethered cord involves progressive neurological symptoms ${ }^{41}$ but nearly all data on this are based on studies of patients without ARMs. ${ }^{8,9,41}$ It is unclear whether the morphological SCAs observed in patients with ARMs behave in the same way. ${ }^{41}$ Caudal regression, meningomyelocele, and Currarino syndrome in association with severe sacral anomalies clearly reflect instances in which significant neurological consequences may be anticipated. ${ }^{1,2,15,27}$ However, the majority of patients with ARMs do not suffer from any of these and have only mild sacral dysplasia at most. The data concerning the influence of isolated SCAs, including low-lying conus medullaris $(\mathrm{CM})$ or filum terminale lipomas, on the functional prognosis in ARMs is unclear., ${ }^{41,31,38}$ Further information on the clinical effects of SCAs in such patients is

ABBREVIATIONS ACE = antegrade continence enema; ARM = anorectal malformation; ASARP, PSARP = anterior, posterior sagittal anorectoplasty; BFS = Bowel Function Score; CM = conus medullaris; LUTS = lower urinary tract symptoms; NS = not significant; RUF = rectourethral fistula; SCA = spinal cord anomaly; TCS = tethered cord syndrome; UTI = urinary tract infection; VF/PF = vestibular and perineal fistula; VUR = vesicoureteric reflux.

SUBMITTED January 8, 2016. ACCEPTED April 27, 2016.

INCLUDE WHEN CITING Published online July 22, 2016; DOI: 10.3171/2016.4.SPINE1641. 
urgently needed, because improvements in MRI screening practices have greatly increased detection rates, ${ }^{41}$ and prophylactic detethering is sometimes performed. $3,39,41$ This study has aimed to compare the long-term outcomes, lower-limb neurological abnormalities, and bowel and lower urinary tract symptoms (LUTS) among patients with ARMs from our institution who also had SCAs that had been managed conservatively, in comparison with patients from our institution with the same types of ARMs but who had a normal spinal cord. To our knowledge, such a detailed comparative evaluation has not been previously undertaken.

\section{Methods \\ Patient Population}

This was a single-institution, cross-sectional study. After institutional ethical board approval, the imaging records of all male patients treated for rectourethral fistula (RUF), and all female patients treated for vestibular or perineal fistula (VF/PF) between 1983 and 2006 were reviewed by a consultant pediatric radiologist who was blinded to the clinical details and outcome. Exclusion criteria were extensive sacral anomalies $(<3$ segments remaining), meningomyelocele, and Currarino syndrome. Case records of eligible patients were reviewed for operative details and lower-limb neurological findings. Bowel function and LUTS were assessed based on a postal questionnaire that had been answered voluntarily by the patients. An independent investigator without involvement in the surgical care of these patients conducted the survey. Patients with major cognitive impairment $(n=2)$ or temporary colostomy at the time of the study $(n=1)$ were excluded from the functional outcomes assessment. Outcomes for patients with SCAs were assessed in relation to patients with the same type of ARM and clinical management but with a normal spinal cord.

\section{Radiological Evaluation}

Termination of the CM inferior to the L-2 endplate by a line subtended perpendicularly to the long axis of the spinal cord was considered abnormal. ${ }^{21,24,38}$ The level of CM termination was confirmed by counting upward from L-5 to overcome the effects of fused, hemi-, extra, and/or transitional vertebrae in the cervicothoracic region, if present. In 1 patient with lumbarization of $\mathrm{S}-1$, this vertebra was identified as L-5, and by counting downward from the last ribbed vertebra (T-12) we established the same conus level. A syrinx was considered to be present if the central canal was $>2 \mathrm{~mm}$ in diameter over a distance of $\geq 2$ vertebral bodies. ${ }^{40}$ A filum terminale lipoma was defined as a fatty mass that connected with the leptomeninges or spinal cord.

\section{Questionnaires Used}

Bowel functional outcomes were assessed according to the multivariate Bowel Function Score (BFS) of Rintala and Lindahl (1995). ${ }^{32}$ Scores have repeatedly correlated closely with clinical outcomes in previous series of multiple patient cohorts, ${ }^{11,26,32}$ and a large pool of control data are available. ${ }^{16}$ We have previously reported the long-term outcomes for bowel function for these patients with $\mathrm{VF}$ /
$\mathrm{PF}^{17}$ and $\mathrm{RUF}{ }^{18}$ and now the data from this survey were reviewed in relation to the presence or absence of SCAs. A BFS of $\geq 17 / 20$, achieved by $\geq 90 \%$ of nearly 600 controls, was taken as the lower limit of normal. ${ }^{16}$ Participants also answered a detailed questionnaire on LUTS, which inquired about a history of urinary tract infection (UTI) (yes/no) and occurrence of urinary urgency, urge incontinence, stress incontinence, straining to begin urination, and leakage of urine without physical activity or apparent need to urinate (response scales: never/seldom/often/ always), based on items adapted from the previously validated Danish Prostatic Symptom Score. ${ }^{36}$

\section{Statistical Analysis}

Data are presented as the median and range. Categorical variables were compared using Fisher's exact test, and continuous variables using the Mann-Whitney U-test. A 2 -tailed $\mathrm{p}$ value $<0.05$ was considered statistically significant.

\section{Results}

\section{Patient Characteristics}

The main patient characteristics are shown in Fig. 1. Of a total of 89 eligible patients (median age 15 years, range 5-29 years), spinal cord MRI was available in 80 (90\%; $50 \%$ male). The median age at MRI was 6 years (range 1.5-28 years). All males with RUF had undergone repair of the ARM with posterior sagittal anorectoplasty (PSARP) under colostomy cover at a median age of 3 months (range 2-24 months). All females with VF/PF had undergone anterior sagittal anorectoplasty (ASARP) at a median age of 3.5 months (range $0.1-48$ months); $50 \%$ of females with a covering colostomy. Four patients $(5 \%$; 3 with a normal spinal cord, 1 with low $\mathrm{CM}$ ) had undergone uncomplicated operative correction of scoliosis: 1 male with RUF due to a lumbar hemivertebra, and 3 others ( 2 males with RUF and 1 female with VF) due to cervicothoracic malsegmentation. No patient in our series had undergone any form of spinal neurosurgical intervention such as detethering surgery; all SCAs had been expectantly managed.

\section{Survey Respondents and Nonrespondents}

Sixty-four patients with normal cognition (83\%; $43 \%$ of whom were males with RUF) returned the survey on functional outcomes, as shown in Fig. 1. No patients were lost to follow-up. The same surgical team had treated and followed up with all patients in this series from birth. $\mathrm{Pa}-$ tients with isolated filum terminale lipomas had been assessed clinically by their consultant pediatric surgeon for any symptoms or signs of lower-limb neurological abnormalities at each follow-up appointment for the ARM. Patients with low CM and/or syrinx additionally underwent regular review by a pediatric neurologist. The median age of the 13 nonrespondents (62\% of whom were males with RUF; $82 \%$ had prostatic fistula) was 21 years (range 16-28 years; $p=$ not significant [NS] vs respondents for all comparisons). The operative treatment by type of ARM and follow-up had been the same as for respondents. Spinal cord anomalies were present in 3 cases (23\%), and mild sacral dysplasia (defined as 3-4 segments remaining) af- 


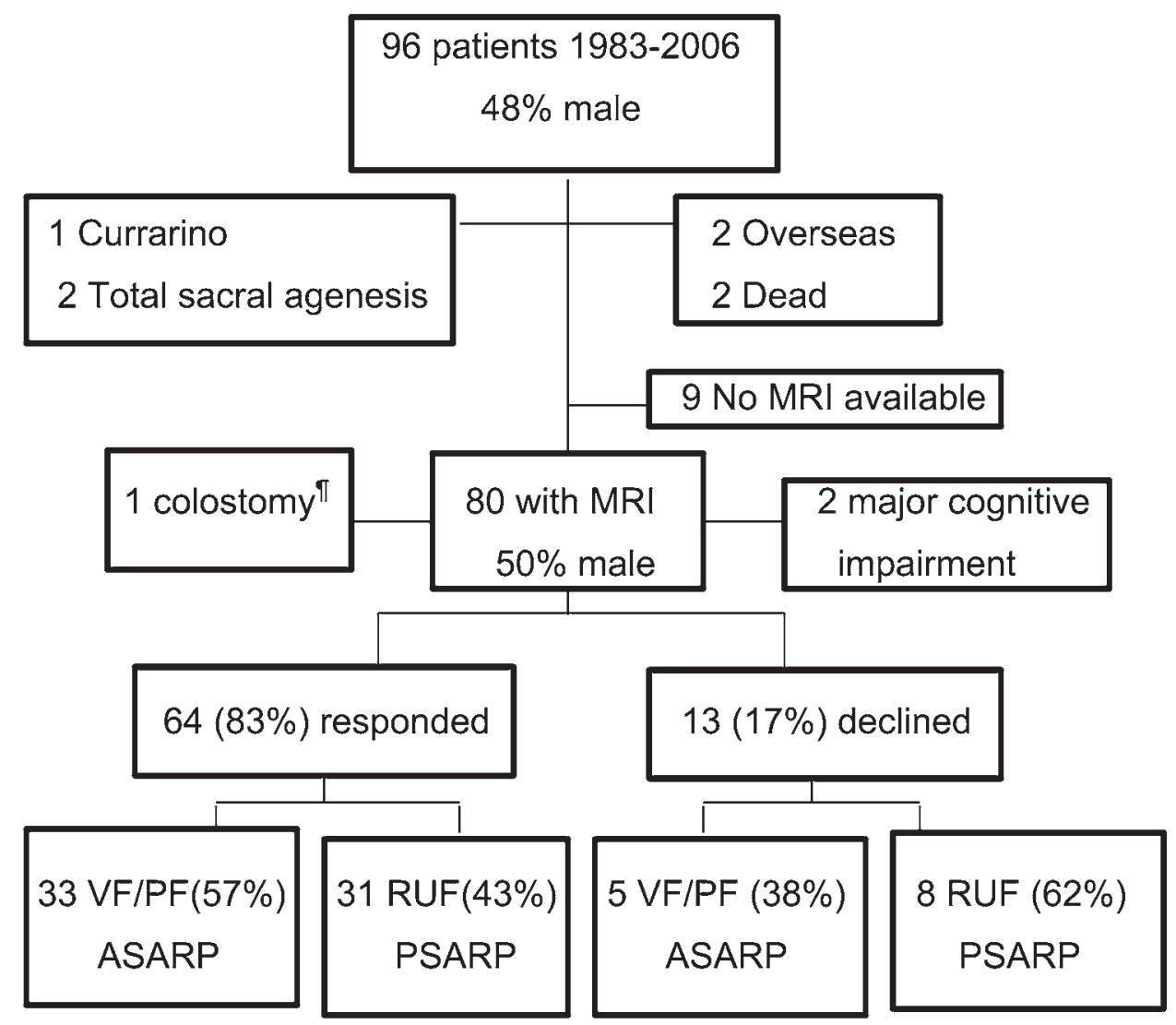

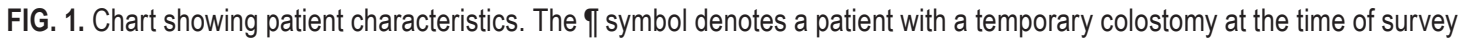
due to uncontrolled diarrhea, normal results on MRI of the sacrum and spine, and no lower-limb symptoms.

fected 2 patients $(15 \% ; \mathrm{p}=$ NS vs respondents for these comparisons).

\section{Prevalence of SCAs}

The data regarding prevalence of SCAs among patients with available imaging $(n=80)$ and by type of ARM are shown in Table 1. Although SCAs affected more females with VF/PF (40\%; $\mathrm{n}=16)$ than males with RUF (28\%; $\mathrm{n}=11$ ) in our cohort, the difference was not statistically significant $(\mathrm{p}=0.22)$. The most common abnormality was a filum terminale lipoma in $30 \%(\mathrm{n}=24)$ of patients. A low-lying CM, up to the upper endplate or body of L-3, was present in 8 cases $(10 \%)$. This was associated with a filum terminale lipoma in 6/8 (75\%) cases and a thoracolumbar syrinx in $3(38 \%)$ cases. Four of 5 patients $(80 \%)$ with thoracolumbar syrinx had an associated low-lying $\mathrm{CM}$ and/or filum terminale lipoma. Mild sacral dysplasia (3-4 segments remaining) was more common among patients with SCAs $(37 \%[\mathrm{n}=10])$ than in patients with a normal spinal cord $(15 \%[n=8] ; p=0.045)$. The median ages of patients with SCAs and those with a normal spinal cord were comparable (15 years, range 5-29 years in both groups; $\mathrm{p}=0.79$ ).

\section{SCAs and Bowel Functional Outcomes}

The controlled bowel functional outcomes in relation to the presence or absence of SCAs, by type of ARM and for the overall cohort, are shown in Table 2. There was no significant difference in the prevalence of soiling, constipation, fecal accidents, requirement for antegrade continence enema (ACE) bowel management, or median BFS between patients with SCAs and patients with a normal spinal cord $(p \geq 0.10)$. The proportion of patients with no bowel symptoms was also comparable between patients with SCAs and those without $(30 \%[\mathrm{n}=7 / 23]$ vs $22 \%$ [n $=9 / 41] ; p=0.55)$. The median BFS between patients with SCAs and a mildly dysplastic sacrum (15, range 7-20) and patients with SCAs but a normal sacrum (16, range 13-20) was not significantly different $(\mathrm{p}=0.71)$. The 2 patients with SCAs and ACE conduits both had a normal sacrum.

\section{SCAs and Prevalence of LUTS and VUR}

As shown in Table 3, there was no significant difference in the prevalence of urinary urge, incontinence of any kind, or straining among patients with SCAs compared with patients without SCAs, whether grouped by ARM or overall ( $\mathrm{p} \geq 0.10$ for all). A history of $\geq 1$ UTI was significantly more common both among patients with SCAs overall $(56 \%$ [n $=13 / 23]$ vs $24 \%[\mathrm{n}=10 / 41]$ in patients without SCAs; $\mathrm{p}=0.01$ ), and among female patients with SCAs $(71 \%$ [ $n=10 / 14]$ vs $25 \%$ [n $=5 / 19]$ in female patients with VF/PF who had a normal spinal cord; $\mathrm{p}=0.02)$. Although vesicoureteric reflux (VUR) was twice as common 
TABLE 1. Prevalence of SCAs among 80 patients with imaging

\begin{tabular}{|c|c|c|c|c|}
\hline \multirow[b]{2}{*}{ SCA } & \multicolumn{3}{|c|}{ No. w/ ARM Type } & \multirow[b]{2}{*}{ p Value* } \\
\hline & $\begin{array}{c}\text { VF/PF, Females; } \\
\quad n=40(\%)\end{array}$ & $\begin{array}{c}\text { RUF, Males; } \\
n=40(\%)\end{array}$ & $\begin{array}{l}\text { All, } n= \\
80(\%)\end{array}$ & \\
\hline $\begin{array}{l}\text { Filum terminale } \\
\text { lipoma }\end{array}$ & $15(38)$ & $9(23)$ & $24(30)$ & NS \\
\hline Low CM† & $4(10)$ & $4(10)$ & $8(10)$ & NS \\
\hline $\begin{array}{l}\text { Thoracolumbar } \\
\text { syrinx }\end{array}$ & $3(8)$ & $2(5)$ & $5(6)$ & NS \\
\hline Any SCA & $16(40)$ & $11(28)$ & $27(34)$ & NS \\
\hline $\begin{array}{l}\text { Mild sacral } \\
\text { dysplasiał }\end{array}$ & $6(15)$ & $10(25)$ & $16(20)$ & NS \\
\hline
\end{tabular}

among female patients with VF/PF who had SCAs (43\% [n $=6 / 14]$ vs $21 \%[\mathrm{n}=4 / 19] ; \mathrm{p}=0.26$ ) and a lower proportion was free of any LUTS than among female patients without SCAs (14\% [n = 2/14] vs $42 \%$ [ $=8 / 19] ; p=0.13)$, the difference was not statistically significant for either in our series. Among respondents with SCAs $(n=23)$, the proportion who were free from LUTS was not significantly different between patients with a mildly dysplastic sacrum $(22 \%[\mathrm{n}=2 / 9])$ and those with a normal sacrum $(14 \%$ [n $=2 / 14] ; \mathrm{p}=1.00)$.

\section{Controlled Outcomes in Patients With SCAs Followed for $>12$ Years}

The controlled outcomes for bowel function and LUTS among patients with SCAs followed up for $>12$ years (n $=13$ ) are shown in Table 4. By this time, there was no significant difference compared with patients without SCAs for any functional parameter, including UTIs ( $p \geq 0.25$ for all).

\section{Outcomes in Respondents With CM Termination Below the L-2 Endplate}

The outcomes among the 6 respondents with CM termination inferior to the L-2 endplate (33\% RUF; median age 9 [range 6-28] years vs 15 [range 5-29] years in pa- tients without SCAs; $p=0.25$ ) were further analyzed as a subgroup. Two patients with low CM had RUF and were only 5 years old at the time of the survey. Four patients $(67 \%)$ had an associated lipoma of the filum terminale. As shown in Table 5, compared with patients with a normal spinal cord, only a history of $\geq 1$ UTI was significantly more common $(83 \%[\mathrm{n}=5 / 6]$ vs $24 \%[\mathrm{n}=10 / 41] ; \mathrm{p}=0.01)$. Urge incontinence $(67 \%$ [ $n=4 / 6]$ vs $24 \%$ [n $=10 / 41] ; p=$ $0.056)$ and constipation $(83 \%[\mathrm{n}=5 / 6]$ vs $39 \%$ [n=16/41]; $\mathrm{p}=0.076)$ tended to be more common among patients with a low-lying CM. Formal examination of lower-limb somatosensory evoked potentials had been performed in $4 / 6$ cases, with a completely normal result in all.

\section{Neurological Outcomes}

During the follow-up period, no patient with or without SCAs developed leg pain or neurological abnormalities in the lower limbs.

\section{Discussion}

This study represents a systematic attempt to compare the prevalence of LUTS and bowel symptoms between patients with ARM in whom SCAs were conservatively managed and patients with the same types of ARM but a normal spinal cord after long-term follow-up. Our study showed that functional bladder and bowel symptoms were common in both groups, and suggested that the prevalence of these symptoms may not be significantly different among patients with ARM in whom SCAs are completely expectantly managed, compared with those patients who have an ARM only. This information is valuable, because prophylactic neurosurgical intervention is practiced in some centers..$^{39}$ To our knowledge, our series represents the largest controlled long-term follow-up study to date of conservatively managed SCAs in the select population of patients with ARM described. Among the strengths of our study are a $90 \%$ spinal MRI availability and an $83 \%$ response rate to the questionnaire survey. An independent investigator also conducted the functional outcomes survey, and the pediatric radiologist who reviewed the imaging was blind to the clinical details and outcome. There was no statistically significant difference in the essential patient characteristics between survey respondents and

TABLE 2. Findings of SCAs and bowel functional outcomes in patients with VF/PF and RUF

\begin{tabular}{|c|c|c|c|c|c|c|c|c|c|}
\hline \multirow[b]{3}{*}{ Outcome } & \multicolumn{9}{|c|}{ No. w/ ARM Type (\%) } \\
\hline & \multicolumn{3}{|c|}{ VF/PF } & \multicolumn{3}{|c|}{ RUF } & \multicolumn{3}{|c|}{ All } \\
\hline & $\begin{array}{l}\text { SCA, } \\
n=14\end{array}$ & $\begin{array}{c}\text { No SCA, } \\
n=19\end{array}$ & p Value ${ }^{*}$ & $\begin{array}{l}\text { SCA, } \\
n=9\end{array}$ & $\begin{array}{c}\text { No SCA } \\
n=22\end{array}$ & p Value ${ }^{*}$ & $\begin{array}{l}\text { SCA, } \\
n=23\end{array}$ & $\begin{array}{c}\text { No SCA, } \\
n=41\end{array}$ & $p$ Value ${ }^{*}$ \\
\hline Soiling & $9(64)$ & $12(63)$ & NS & $7(78)$ & $14(64)$ & NS & $16(70)$ & $26(63)$ & NS \\
\hline Fecal accidents & $4(29)$ & $3(16)$ & NS & $6(67)$ & $11(50)$ & NS & $10(43)$ & $14(34)$ & NS \\
\hline Constipation & $7(50)$ & $8(42)$ & NS & $6(67)$ & $8(36)$ & NS & $13(57)$ & $16(39)$ & NS \\
\hline ACE conduit & 0 & 0 & NS & $2(22)$ & $5(23)$ & NS & $2(9)$ & $5(12)$ & NS \\
\hline Median BFS (range) $\dagger$ & $15(7-20)$ & $18(13-20)$ & NS & $15(7-20)$ & $18(13-20)$ & NS & $16(7-20)$ & $18(13-20)$ & NS \\
\hline No bowel symptoms & $4(29)$ & $5(26)$ & NS & $3(33)$ & $4(18)$ & NS & $7(30)$ & $9(22)$ & NS \\
\hline
\end{tabular}

${ }^{*} p \geq 0.10$ is expressed as NS.

$\dagger$ Maximum BFS 20, normal score $\geq 17$; available for patients without ACE. 
TABLE 3. Findings of SCAs and prevalence of LUTS and VUR among patients with VF/PF and RUF

\begin{tabular}{|c|c|c|c|c|c|c|c|c|c|}
\hline \multirow[b]{3}{*}{ LUTS } & \multicolumn{9}{|c|}{ No. w/ ARM Type (\%) } \\
\hline & \multicolumn{3}{|c|}{ VF/PF } & \multicolumn{3}{|c|}{ RUF } & \multicolumn{3}{|c|}{ All } \\
\hline & $\begin{array}{l}\text { SCA, } \\
n=14\end{array}$ & $\begin{array}{c}\text { No SCA } \\
\mathrm{n}=19\end{array}$ & $p$ Value* & $\begin{array}{l}\text { SCA } \\
n=9\end{array}$ & $\begin{array}{c}\text { No SCA, } \\
n=22\end{array}$ & $p$ Value* & $\begin{array}{l}S C A \\
n=23\end{array}$ & $\begin{array}{c}\text { No SCA, } \\
n=41\end{array}$ & p Value* \\
\hline UTI & $10(71)$ & $5(26)$ & 0.02 & $3(33)$ & $5(23)$ & NS & $13(57)$ & $10(24)$ & 0.01 \\
\hline Urge & $9(64)$ & $9(47)$ & NS & $6(67)$ & $13(59)$ & NS & $15(65)$ & $22(54)$ & NS \\
\hline Urge incontinence & $7(50)$ & $5(26)$ & NS & $2(22)$ & $5(23)$ & NS & $9(39)$ & $10(24)$ & NS \\
\hline Stress incontinence & $4(29)$ & $6(32)$ & NS & $0(0)$ & $3(14)$ & NS & $4(17)$ & $9(22)$ & NS \\
\hline Any urinary incontinence & $7(50)$ & $8(42)$ & NS & $2(22)$ & $5(23)$ & NS & $9(39)$ & $13(32)$ & NS \\
\hline Straining & $3(21)$ & $4(21)$ & NS & $4(44)$ & $8(36)$ & NS & $7(30)$ & $12(29)$ & NS \\
\hline Initial VUR & $6(43)$ & $4(21)$ & NS & $3(33)$ & $6(27)$ & NS & $9(39)$ & $10(24)$ & NS \\
\hline No LUTS & $2(14)$ & $8(42)$ & NS & $2(22)$ & $6(27)$ & NS & $4(17)$ & $14(34)$ & NS \\
\hline
\end{tabular}

* $p \geq 0.10$ expressed as NS.

nonrespondents, which reduces the possibility of selection bias affecting the results. Patients had been followed up from birth.

Our results confirm the findings of others ${ }^{5,14,34}$ that SCAs, and filum terminale lipomas in particular, are common among patients with ARMs (Table 1). Importantly, our results suggest that the natural history of SCAs in those among our cohort of 64 patients with VF/PF or RUF who had mild or no sacral dysplasia (3-4 segments remaining) was benign and nonprogressive. Although there is very limited data available on conservatively managed SCAs among patients with ARMs, other investigators have also reported on patients with ARMs who have presented with morphological cord tethering and who have remained entirely stable during clinical follow-up. ${ }^{21,37}$ Likewise, although studies in patients with ARMs are not available, in 32 cases of idiopathic syrinx in children, the patients remained asymptomatic, stable, or improved under conservative follow-up in $91 \%$ of cases in one combined-center study. ${ }^{22}$

TABLE 4. Controlled outcomes for bowel function and LUTS in patients with SCAs followed for $>12$ years

\begin{tabular}{lccc}
\hline \multicolumn{1}{c}{ Outcome } & $\begin{array}{c}\mathrm{SCA}(\%), \\
\mathrm{n}=13\end{array}$ & $\begin{array}{c}\text { No SCA }(\%), \\
\mathrm{n}=26\end{array}$ & $\mathrm{p} \mathrm{Value}$ \\
\hline Soiling & $8(62)$ & $16(62)$ & $\mathrm{NS}$ \\
\hline Fecal accidents & $5(38)$ & $9(35)$ & $\mathrm{NS}$ \\
\hline Constipation & $4(31)$ & $5(19)$ & $\mathrm{NS}$ \\
\hline No bowel symptoms & $6(46)$ & $7(27)$ & $\mathrm{NS}$ \\
\hline UTI & $6(46)$ & $8(31)$ & $\mathrm{NS}$ \\
\hline Urge & $9(69)$ & $14(54)$ & $\mathrm{NS}$ \\
\hline Urge incontinence & $2(15)$ & $1(4)$ & $\mathrm{NS}$ \\
\hline Stress incontinence & $2(15)$ & $4(15)$ & $\mathrm{NS}$ \\
\hline Any urinary incontinence & $4(31)$ & $6(23)$ & $\mathrm{NS}$ \\
\hline Straining & $4(31)$ & $8(31)$ & $\mathrm{NS}$ \\
\hline No LUTS & $2(15)$ & $9(35)$ & $\mathrm{NS}$ \\
\hline Abnormal lower-limb neurological \\
$\quad 0(0)$ & $0(0)$ & $\mathrm{NS}$ \\
$\quad$ findings & & & \\
\hline${ }^{*} \mathrm{p} \geq 0.25$ for all comparisons. & & &
\end{tabular}

In our series, the prevalence of functional bowel symptoms and LUTS, apart from UTIs, was entirely comparable between patients with ARM who have SCAs compared with those with a normal spinal cord. The higher prevalence of UTIs in the SCA group overall $(56 \%$ [n $=13 / 23]$ vs $24 \%[\mathrm{n}=10 / 41] ; \mathrm{p}=0.01$; Table 3$)$, but not among patients followed up for $>12$ years $(46 \%[n=6 / 13]$ vs $31 \%[n=8 / 26] ; p=N S$; Table 4$)$, could relate to the higher prevalence of initial VUR among our female patients with VF/PF and SCAs (43\% [n=6/14] vs $21 \%[n$ $=4 / 19$ ] in female patients without SCAs; $p=0.26$; Table 3) although the difference in VUR was not statistically significant in our series. Unfortunately, our survey did not inquire about the timing of the last UTI or the actual number of infections, which would have given a better picture. Previous urodynamic investigation of patients with ARMs

TABLE 5. Controlled outcomes for patients with CM below the L-2 endplate

\begin{tabular}{|c|c|c|c|}
\hline Outcome & $\begin{array}{c}\text { Low CM (\%), } \\
n=6\end{array}$ & $\begin{array}{c}\text { No SCA }(\%), \\
n=41\end{array}$ & $p$ Value* \\
\hline Soiling & $4(67)$ & $26(63)$ & NS \\
\hline Fecal accidents & $3(50)$ & $14(34)$ & NS \\
\hline Constipation & $5(83)$ & $16(39)$ & 0.076 \\
\hline ACE & $1(17)$ & $5(12)$ & NS \\
\hline No bowel symptoms & $1(17)$ & $9(22)$ & NS \\
\hline Sacral dysplasia† & $2(33)$ & $6(15)$ & NS \\
\hline UTI & $5(83)$ & $10(24)$ & 0.01 \\
\hline Urge & $5(83)$ & $22(54)$ & NS \\
\hline Urge incontinence & $4(67)$ & $10(24)$ & 0.056 \\
\hline Stress incontinence & $0(0)$ & $9(22)$ & NS \\
\hline Any incontinence & $4(67)$ & $13(32)$ & NS \\
\hline Straining & $2(33)$ & $12(29)$ & NS \\
\hline VUR & $1(17)$ & $10(24)$ & NS \\
\hline No LUTS & $0(0)$ & $14(34)$ & NS \\
\hline $\begin{array}{l}\text { Abnormal lower-limb neuro- } \\
\text { logical findings }\end{array}$ & $0(0)$ & $0(0)$ & NS \\
\hline
\end{tabular}


did not find any association between the LUTS profile and the presence or absence of SCAs..$^{38}$ Our data did not demonstrate any effect from mild sacral dysplasia on the overall BFS or prevalence of LUTS.

The term tethered cord syndrome (TCS) refers to a condition arising from traction on the spinal cord. ${ }^{6,21,30}$ It represents both an individual diagnosis and a combination of signs and symptoms, including bladder and bowel dysfunction and orthopedic effects such as pain radiating to the lower limbs and progressive lower-limb palsy. ${ }^{30,35}$ Morphologically, its appearance entails termination of the CM below the L-2 vertebra in both adults and children, $6,13,42$ although clinical signs consistent with TCS have also been described in association with isolated filum terminale lipomas $^{23}$ and thickening of the filum terminale $>2 \mathrm{~mm}$ and a normally positioned CM. ${ }^{6,28,31}$ Conversely, filum terminale lipomas or thickening have been reported in 6\%-17\% of normal subjects. ${ }^{23,30}$ It should be noted that CM termination up to the body of L-3 is sometimes found in normal neonates and does not automatically equate to anatomical abnormality in this age group., ${ }^{7,42}$

Correlation of the radiological findings with clinical symptoms is essential for the diagnosis of TCS. ${ }^{6}$ Among patients with ARM, however, LUTS and bowel symptoms are generally common anyway,,$^{10,29,38}$ and are not only limited to patients with SCAs. The results of the current series of patients with ARM who had mild or no sacral dysplasia did not suggest an effect from the radiologically observed SCAs on bowel function and overall LUTS profile during long-term follow-up. Apart from UTIs, there was no significant difference in the prevalence of LUTS (Table 3) or impairment of fecal control (Table 2) between patients with SCAs and those with a normal spinal cord ( $\mathrm{p}=\mathrm{NS}$ for all). This did not alter with increasing age (Table 4), or even among patients with low CM (Table 5), although the data for low CM are based on small patient numbers and should therefore be interpreted with some caution. Bowel functional symptoms are generally more prevalent among patients with RUF who are $<12$ years of age than in teenagers, ${ }^{18}$ and $2 / 6$ patients with low CM had RUF and were only 5 years old at the time of the survey. Termination of the $\mathrm{CM}$ below the body of L-3 was not observed in this cohort.

No patient with SCAs in our series developed leg pain or lower-limb neurological impairment over the follow-up period of up to 29 years. The somatosensory evoked potential studies performed in patients with low CM confirmed the clinical impressions. It has been previously suggested that motor and neurological symptoms attributable to TCS affect $<2 \%$ of all patients with ARMs. ${ }^{40}$ Although severe sacral defects such as total agenesis, hemisacrum, or caudal regression and meningomyelocele are associated with significant clinical manifestations of spinal dysraphism, ${ }^{15}$ these conditions do not affect the majority of patients with ARMs, and hence should be studied and considered separately.

An important limitation to acknowledge in our study is patient numbers, particularly for patients with low CM, which opens the possibility of Type II error in the results. The problem of numbers is a limitation of practically all single-center studies of patients with ARM, because of the relative rarity of ARMs. Patients with cloacal malforma- tions were also not studied here, but will form part of our future work. Unfortunately, we were unable to include patients with milder forms of ARMs due to incomplete MRI records for this population. However, we have previously shown that over time bowel function and LUTS become comparable to the general population in the vast majority of these patients with appropriate aftercare, ${ }^{19,20}$ and the gaps in records are mostly related to an absence of clinical symptoms that would have prompted investigation. There is also no reason to believe that SCAs in patients with mild ARMs would exhibit a different clinical course from SCAs in patients with more severe malformations, although further multicenter studies involving larger numbers of patients are needed to confirm this and our current findings.

There are only a few series examining the outcomes of detethering procedures specifically in patients with ARM, and these have not suggested any evidence that operative intervention improves the bladder and bowel symptoms in these patients. $3,12,21,39,41,43$ However, alleviation of limb motor and sensory symptoms in at least a proportion of patients has been reported by several investigators, and surgery may have a role in these carefully selected cases. ${ }^{21,37,41}$ The results of our current study favor a conservative approach to the management of SCAs in patients with ARM who have mild or no sacral dysplasia ( $\geq 3$ segments remaining) and no limb motor or sensory dysfunction.

In terms of screening, spinal ultrasound during the neonatal period forms part of our routine management in all patients with ARMs. Whole-spine MRI screening has been systematically practiced for patients with moderate to severe ARMs during childhood, and among patients with milder ARMs to a lesser extent. Because this is a retrospective series, MR scanning had been performed at varying ages-but in all cases at an age at which the CM position should have been established. Although lowerlimb neurological abnormalities did not develop among our patient population and our management approach has been conservative, regular neurological surveillance of patients with ARM in whom SCAs are present remains advisable.

\section{Conclusions}

Our controlled, cross-sectional study suggests that the long-term functional outcomes for SCAs among patients with VF/PF and RUF who have SCAs and minor or no sacral dysplasia were not significantly different from those in patients with the same type of ARMs but a normal spinal cord after conservative, expectant management. The results support a nonoperative approach to management in the absence of neurological abnormalities of the lower limbs, but further multicenter studies are needed to confirm findings.

\section{Acknowledgments}

This research was supported by grants from the Foundation for Pediatric Research (Finland), the Sigrid Juselius Foundation, and the Helsinki University Central Hospital research funds.

\section{References}

1. Borg H, Holmdahl G, Olsson I, Wiklund LM, Sillén U: 
Impact of spinal cord malformation on bladder function in children with anorectal malformations. J Pediatr Surg 44:1778-1785, 2009

2. Borg HC, Holmdahl G, Gustavsson K, Doroszkiewicz M, Sillén U: Longitudinal study of bowel function in children with anorectal malformations. J Pediatr Surg 48:597-606, 2013

3. Davidoff AM, Thompson CV, Grimm JM, Shorter NA, Filston HC, Oakes WJ: Occult spinal dysraphism in patients with anal agenesis. J Pediatr Surg 26:1001-1005, 1991

4. Di Cesare A, Leva E, Macchini F, Canazza L, Carrabba G, Fumagalli M, et al: Anorectal malformations and neurospinal dysraphism: is this association a major risk for continence? Pediatr Surg Int 26:1077-1081, 2010

5. Herman RS, Teitelbaum DH: Anorectal malformations. Clin Perinatol 39:403-422, 2012

6. Hertzler DA II, DePowell JJ, Stevenson CB, Mangano FT: Tethered cord syndrome: a review of the literature from embryology to adult presentation. Neurosurg Focus 29(1):E1, 2010

7. Hill CA, Gibson PJ: Ultrasound determination of the normal location of the conus medullaris in neonates. AJNR Am J Neuroradiol 16:469-472, 1995

8. Hüttmann S, Krauss J, Collmann H, Sörensen N, Roosen K: Surgical management of tethered spinal cord in adults: report of 54 cases. J Neurosurg 95 (2 Suppl):173-178, 2001

9. Iskandar BJ, Fulmer BB, Hadley MN, Oakes WJ: Congenital tethered spinal cord syndrome in adults. J Neurosurg 88:958-961, 1998

10. Iwai N, Fumino S: Surgical treatment of anorectal malformations. Surg Today 43:955-962, 2013

11. Jarvi K, Laitakari EM, Koivusalo A, Rintala RJ, Pakarinen MP: Bowel function and gastrointestinal quality of life among adults operated for Hirschsprung disease during childhood: a population-based study. Ann Surg 252:977981, 2010

12. Karrer FM, Flannery AM, Nelson MD Jr, McLone DG, Raffensperger JG: Anorectal malformations: evaluation of associated spinal dysraphic syndromes. J Pediatr Surg 23:45-48, 1988

13. Kesler H, Dias MS, Kalapos P: Termination of the normal conus medullaris in children: a whole-spine magnetic resonance imaging study. Neurosurg Focus 23(2):E7, 2007

14. Kim SM, Chang HK, Lee MJ, Shim KW, Oh JT, Kim DS, et al: Spinal dysraphism with anorectal malformation: lumbosacral magnetic resonance imaging evaluation of 120 patients. J Pediatr Surg 45:769-776, 2010

15. Kole MJ, Fridley JS, Jea A, Bollo RJ: Currarino syndrome and spinal dysraphism. J Neurosurg Pediatr 13:685-689, 2014

16. Kyrklund K, Koivusalo A, Rintala RJ, Pakarinen MP: Evaluation of bowel function and fecal continence in 594 Finnish individuals aged 4 to 26 years. Dis Colon Rectum 55:671676, 2012

17. Kyrklund K, Pakarinen MP, Koivusalo A, Rintala RJ: Bowel functional outcomes in females with perineal or vestibular fistula treated with anterior sagittal anorectoplasty: controlled results into adulthood. Dis Colon Rectum 58:97-103, 2015

18. Kyrklund K, Pakarinen MP, Koivusalo A, Rintala RJ: Longterm bowel functional outcomes in rectourethral fistula treated with PSARP: controlled results after 4-29 years of follow-up: a single-institution, cross-sectional study. J Pediatr Surg 49:1635-1642, 2014

19. Kyrklund K, Pakarinen MP, Taskinen S, Rintala RJ: Bowel function and lower urinary tract symptoms in females with anterior anus treated conservatively: controlled outcomes into adulthood. J Pediatr Surg 50:1168-1173, 2015

20. Kyrklund K, Pakarinen MP, Taskinen S, Rintala RJ: Bowel function and lower urinary tract symptoms in males with low anorectal malformations: an update of controlled, long-term outcomes. Int J Colorectal Dis 30:221-228, 2015

21. Levitt MA, Patel M, Rodriguez G, Gaylin DS, Peña A: The tethered spinal cord in patients with anorectal malformations. J Pediatr Surg 32:462-468, 1997

22. Magge SN, Smyth MD, Governale LS, Goumnerova L, Madsen J, Munro B, et al: Idiopathic syrinx in the pediatric population: a combined center experience. J Neurosurg Pediatr 7:30-36, 2011

23. McLendon RE, Oakes WJ, Heinz ER, Yeates AE, Burger PC: Adipose tissue in the filum terminale: a computed tomographic finding that may indicate tethering of the spinal cord. Neurosurgery 22:873-876, 1988

24. Morimoto T, Sonohata M, Kitajima M, Konishi H, Otani K, Kikuchi S, et al: The termination level of the conus medullaris and lumbosacral transitional vertebrae. J Orthop Sci 18:878-884, 2013

25. Nah SA, Ong CC, Lakshmi NK, Yap TL, Jacobsen AS, Low Y: Anomalies associated with anorectal malformations according to the Krickenbeck anatomic classification. J Pediatr Surg 47:2273-2278, 2012

26. Pakarinen MP, Koivusalo A, Lindahl H, Rintala RJ: Prospective controlled long-term follow-up for functional outcome after anoplasty in boys with perineal fistula. J Pediatr Gastroenterol Nutr 44:436-439, 2007

27. Pang D: Sacral agenesis and caudal spinal cord malformations. Neurosurgery 32:755-779, 1993

28. Pang D, Wilberger JE Jr: Tethered cord syndrome in adults. J Neurosurg 57:32-47, 1982

29. Peña A, Hong A: Advances in the management of anorectal malformations. Am J Surg 180:370-376, 2000

30. Pinto FCG, de Vasconcellos Fontes RB, de Camargo Leonhardt M, Amodio DT, Porro FF, Machado J: Anatomic study of the filum terminale and its correlations with the tethered cord syndrome. Neurosurgery 51:725-730, 2002

31. Raghavan N, Barkovich AJ, Edwards M, Norman D: MR imaging in the tethered spinal cord syndrome. AJR Am J Roentgenol 152:843-852, 1989

32. Rintala RJ, Lindahl H: Is normal bowel function possible after repair of intermediate and high anorectal malformations? J Pediatr Surg 30:491-494, 1995

33. Rintala RJ, Pakarinen MP: Outcome of anorectal malformations and Hirschsprung's disease beyond childhood. Semin Pediatr Surg 19:160-167, 2010

34. Rivosecchi M, Lucchetti MC, Zaccara A, De Gennaro M, Fariello G: Spinal dysraphism detected by magnetic resonance imaging in patients with anorectal anomalies: incidence and clinical significance. J Pediatr Surg 30:488-490, 1995

35. Safavi-Abbasi S, Mapstone TB, Archer JB, Wilson C, Theodore N, Spetzler RF, et al: History of the current understanding and management of tethered spinal cord. J Neurosurg Spine 25:78-87, 2016

36. Schou J, Poulsen AL, Nordling J: The value of a new symptom score (DAN-PSS) in diagnosing uro-dynamic infravesical obstruction in BPH. Scand J Urol Nephrol 27:489-492, 1993

37. Suppiej A, Dal Zotto L, Cappellari A, Traverso A, Castagnetti M, Drigo P, et al: Tethered cord in patients with anorectal malformation: preliminary results. Pediatr Surg Int 25:851-855, 2009

38. Taskinen S, Valanne L, Rintala R: Effect of spinal cord abnormalities on the function of the lower urinary tract in patients with anorectal abnormalities. J Urol 168:1147-1149, 2002

39. Teo ATK, Gan BK, Tung JSZ, Low Y, Seow WT: Low-lying spinal cord and tethered cord syndrome in children with anorectal malformations. Singapore Med J 53:570-576, 2012 
40. Tsitouras V, Sgouros S: Syringomyelia and tethered cord in children. Childs Nerv Syst 29:1625-1634, 2013

41. Tuuha SE, Aziz D, Drake J, Wales P, Kim PC: Is surgery necessary for asymptomatic tethered cord in anorectal malformation patients? J Pediatr Surg 39:773-777, 2004

42. Van Schoor AN, Bosman MC, Bosenberg AT: Descriptive study of the differences in the level of the conus medullaris in four different age groups. Clin Anat 28:638-644, 2015

43. Warf BC, Scott RM, Barnes PD, Hendren WH III: Tethered spinal cord in patients with anorectal and urogenital malformations. Pediatr Neurosurg 19:25-30, 1993

\section{Disclosures}

The authors report no conflict of interest concerning the materials or methods used in this study or the findings specified in this paper.

\section{Author Contributions}

Conception and design: all authors. Acquisition of data: all authors. Analysis and interpretation of data: all authors. Drafting the article: all authors. Critically revising the article: all authors. Reviewed submitted version of manuscript: all authors. Approved the final version of the manuscript on behalf of all authors: Kyrklund. Statistical analysis: Kyrklund, Pakarinen, Taskinen, Rintala. Study supervision: Pakarinen, Rintala.

\section{Supplemental Information}

Previous Presentations

The abstract for this manuscript was presented at the European Pediatric Surgeon's Association Congress, which was held in Rome, Italy, on June 17-20, 2015.

\section{Correspondence}

Kristiina Kyrklund, Department of Pediatric Surgery, Hospital for Children and Adolescents, University of Helsinki, PL 281, Helsinki 00029 HUS, Finland. email: kristiinakyrklund@yahoo. com 